\title{
The Challenges and Opportunities Associated with Reimbursement for Obesity Pharmacotherapy in the USA
}

\author{
Charles Baum • Katherine Andino • \\ Eric Wittbrodt • Shelley Stewart • Keith Szymanski • \\ Robin Turpin
}

Published online: 17 February 2015

(c) The Author(s) 2015. This article is published with open access at Springerlink.com

\begin{abstract}
Obesity has become a serious public health problem that has stimulated primordial and primary prevention efforts, and a triad of management options (lifestyle, pharmacotherapy, and surgical interventions). A growing body of evidence supports the need for a multi-pronged, clinic-based approach that leverages the synergy between pharmaceutical and lifestyle modification. Recent US policy changes-namely, the passage of the Patient Protection and Affordable Care Act coupled with recognition of obesity as a disease by the American Medical Association-suggest that financial incentives and attitudes towards obesity management are changing. This paradigm shift has implications for current and future obesity pharmacotherapy. However, barriers to pharmacotherapy utilization include patient and physician perceptions of modest efficacy, historical safety issues, regulatory obstacles, and lack of reimbursement. The shifting attitudes and challenges associated not only with a multi-payer system, but also the lack of clearly defined crosspayer reimbursement strategies, prompted a survey to determine coverage for obesity treatment. Participants indicated that federal/state mandates and growth of qualitydriven healthcare initiatives will eventually drive wider pharmacotherapy reimbursement within 1-5 years. There
\end{abstract}

C. Baum $(\bowtie) \cdot$ E. Wittbrodt · K. Szymanski · R. Turpin U.S. Medical Affairs, Takeda Pharmaceuticals U.S.A., One Takeda Parkway, Deerfield, IL 60015, USA

e-mail: charles.baum@takeda.com

K. Andino

Obesity Marketing, Takeda Pharmaceuticals U.S.A., Deerfield, IL, USA

S. Stewart

Federal Government and External Affairs, Takeda

Pharmaceuticals America, Inc., 750 9th Street, NW, Suite 575,

Washington DC, USA are signs that federal/state programs are already moving towards reimbursement by improving quality measures to track obesity outcomes and reduce costs. Future research on clinical and economic outcomes of combination weightmanagement programs coupled with innovative approaches (e.g., eHealth) in the real-world setting that demonstrate value to patients, healthcare providers, payers, and employers will help reshape obesity management by reducing barriers and broadening reimbursement coverage for antiobesity pharmacotherapy.

\section{Key Points for Decision Makers}

Obesity pharmaceuticals have historically suffered from drug-related tolerability/safety issues; however, heightened scrutiny during drug development and the mandatory inclusion of long-term cardiovascular safety studies has led to a growing number of safer treatment options.

There are multiple barriers to the widespread adoption of obesity pharmaceuticals in medical practice: patient perceptions and treatment expectations, lack of resources to address the full range of obesity lifestyle and environmental determinants, and limited health insurance coverage for treatment and medication.

\section{Introduction}

Obesity—defined by the US National Heart Lung Blood Institute (NHLBI) as a body mass index (BMI) $\geq 30.0 \mathrm{~kg} /$ $\mathrm{m}^{2}$ [1] - has become a serious global public health problem disproportionately affecting developed countries $[2,3]$ and 
reaching epidemic proportions in the USA [4-6]. Efforts to limit the spread of obesity [7] have addressed both prevention and treatment. Preventive approaches have encompassed lifestyle modification interventions (e.g., diet and exercise) [8,9], public education on nutrition [10], and efforts to increase access to nutritious food options [11,12] and promote healthy eating (including regulation of the food industry $[13,14])$. In addition, treatment efforts have included a triad of long-term therapeutic options: lifestyle modification such as behavioral therapy (BT), pharmacotherapy, and surgical treatment $[15,16]$.

Preventive efforts have seen some success [17-19], but not enough [20] to reverse the increasing obesity incidence in developed countries [3]. Clinical management efforts also face substantial difficulties, despite promising clinical trial results. Clinical trials of behavior and/or lifestyle modification have shown modest weight loss and beneficial effects on glycemic control, cardiovascular risk factors, and development of type 2 diabetes mellitus [21-26], but these findings have been difficult to translate into primary care settings for a number of reasons. First, these interventions are resource-intensive and require specially trained personnel such as behavioral psychologists, dietitians, and health coaches. Second, they often involve one-on-one or group sessions that require clinic space as well as repeat and frequent clinic visits, which, taken together, are financially unsustainable given the lack of commercial insurance reimbursement [27]. Third, physicians ably manage obesityrelated co-morbid conditions, cardiovascular risk factors, and mechanical complications including obstructive sleep apnea [28, 29]. While aware of the need to address obesity, physicians lack adequate tools or support systems and, consequently, rarely assess the goals of treatment or provide motivational support or referral to weight-management counseling [30]. The US Patient Protection and Affordable Care Act (PPACA) [31] emphasizes the importance of prevention in primary care as a way to improve outcomes and reduce cost. However, without additional tools, and confronted with competing priorities, physician efforts against obesity remain modest. Recent data suggest that preventive health efforts have started to flatten the childhood obesity curves, though the opposite is true for rates of extreme obesity [32]. In addition, the modest degrees of weight loss observed with behavioral interventions have led to a rapidly growing specialization in surgical obesity treatment programs. An analysis by the Agency for Healthcare Research and Quality showed that the number of bariatric surgeries, which is generally reserved for highly motivated patients with a BMI cutpoint of $\geq 40$ or $\geq 35 \mathrm{~kg} / \mathrm{m}^{2}$ with an obesity-related co-morbid condition [1], grew ninefold from 1998 to 2004 [33]; further, the use of lap-band surgery was recently expanded by the US Food and Drug Administration (FDA) to include patients with a BMI of $\geq 30.0 \mathrm{~kg} / \mathrm{m}^{2}$ with an existing condition related to their obesity [34]. A review of the different surgical treatment options is beyond the scope of this paper, but bariatric surgery has the demonstrated benefits of rapid and substantial weight loss and clinically important improvements in some biomarkers of co-morbid disease [35-37]. Unfortunately, recent studies of long-term outcomes with bariatric surgery show weight loss is sometimes not sustained; recidivism after surgery can be significant $[38,39]$; and reoperation can be necessary with an attendant increase in operative and post-operative morbidity and mortality [40].

The option of obesity pharmacotherapy, coupled with new and advanced minimal-contact behavioral modification and lifestyle change programs [41], represent another treatment option. Pharmacotherapy is recommended as an adjunct to lifestyle modification in obese individuals with a BMI of $\geq 30.0$, or $\geq 27 \mathrm{~kg} / \mathrm{m}^{2}$ with an obesity-related comorbid condition [1], and recent results support that combining pharmacotherapy with lifestyle intervention leads to greater weight loss than either therapy alone [42]. While pharmacotherapy-assisted weight loss is also subject to recidivism, evidence shows that weight regain may be slowed or prevented with continued medication use [1].

The economic consequences of obesity and its associated co-morbidities are staggering and 2008 US estimates suggest that annual aggregate medical spending may be as high as \$US147 billion per year [43]. Efforts to curb healthcare spending in the USA have focused on obesity as an upstream driver of multiple chronic diseases and support the case for a comprehensive, multifaceted approach to the obesity epidemic. At an individual patient level, little data exist to support the effectiveness of non-surgical treatment on healthcare cost; however, a recent study from the University of Michigan reported promising data on a realworld treatment that reduced healthcare utilization and cost in as little as 1 year [44].

It is within the context of real-world observational analyses afforded by the vertical integration of the US healthcare system and the alignment of stakeholders on pay-for-performance for improved outcomes and cost savings that we believe the cost benefit of pharmacotherapy will be demonstrated. This review provides an update and perspective on the evolving healthcare determinants, which, when coupled with obesity pharmacotherapy cost benefit, may drive future insurance reimbursement and greater patient access to treatment.

\section{Previous Anti-Obesity Drugs and Implications for Current Pharmacologic Treatment}

Although the first anti-obesity drug desoxyephedrine (or methamphetamine) was approved by the FDA in 1947, and 
the most commonly prescribed medication phentermine was approved in 1959, sales of drugs with this indication did not accelerate until the early 1990s [45]. During this period, obesity prevalence rapidly increased [46] and the contribution of obesity to the development or worsening of a large number of medical conditions was better recognized $[47,48]$. Yet, the adverse effects associated with these early drugs were considered too dangerous or undesirable for long-term use, thus limiting physician treatment options [45]. The obesity drug combination of fenfluramine/phentermine (known as fen-phen) was serendipitously discovered through clinical trial and error. Fen-phen had potent anorectic effects and consequently gained popularity in the early 1990s, reaching a peak of 18 million prescriptions in 1996 [49] despite the absence of FDA approval [50]. Fenfluramine (with its derivative dexfenfluramine or Re$\operatorname{dux}^{\mathrm{TM}}$ ) was withdrawn from use in the USA in 1997 amid a major safety signal from reports of increased rates of valvular heart damage, primary pulmonary hypertension, and other severe complications associated with long-term use [51]. After the fen-phen experience, sibutramine entered the anti-obesity field in 1997, orlistat in 1999, and rimonabant was approved for use in the European Union in 2006. While showing some initial success, concerns about the weak efficacy of some of these agents, disruptive adverse events in the case of orlistat (e.g., bloating, flatulence, and diarrhea), cardiovascular risks with sibutramine (leading to its subsequent withdrawal in 2010), and depressive/suicidal reactions with rimonabant (withdrawn in 2009) ultimately led to a steady decline in weight-loss drug sales. Consequently, global revenue of anti-obesity drugs went from an estimated \$US870 million in 2000 [52] to \$US677 million in 2009 [53], then to \$US359 million in 2011 [54].

Since 2012, three anti-obesity drugs have received regulatory approval in the USA (lorcaserin [55], phentermine/topiramate combination [56], and bupropion SR [sustained-release formulation]/naltrexone SR combination [57]) after additional regulatory demands and delays [58]. These anti-obesity pharmacotherapy options along with orlistat remain available for long-term treatment; however, phentermine is currently the most commonly prescribed anorectic agent despite FDA labeling that limits use to 3 months or less.

The recent successful approval of three new anti-obesity agents belies a number of barriers. First, drug development is both costly and risky. Between 1993 and 1994, only $7.9 \%$ of all compounds first tested in humans received regulatory approval [59], and \$US0.8-1.2 billion was spent on average for each new drug development [60-63]. While the probability of regulatory approval is estimated to be $19 \%$ for applications across drug classes [59], the historical success rate (1993-2004) for medications affecting metabolism/the gastrointestinal system and the central nervous system has been much lower-3.3-3.8 \% [59] - and reflects the difficulty in finding targets that are free from metabolic redundancy and safety issues. Nonetheless, regulatory approval is particularly difficult to obtain for anti-obesity drugs [64, 65], and the FDA now requires the results of a long-term cardiovascular outcomes trial in the applications.

On top of drug development and approval barriers, pharmaceutical companies have largely relied on patient and physician acceptance of out-of-pocket reimbursement. Low rates of insurance reimbursement remain a major barrier, despite clinical guidelines recommending the use of anti-obesity drugs $[15,66]$. Insurance coverage has generally been confined to employer-sponsored insurance plans with no government reimbursement [67, 68]. Finally, the lack of insurance has precluded long-term treatment and led to reluctance to prescribe due to the belief that weight regain post short-term treatment is likely. These treatment barriers taken together with historical safety issues have led providers to resist prescribing anti-obesity medications [68, 69]. However, the multiple factors affecting anti-obesity medication use have not seemed to slow the influence from pharmaceutical companies, and pipelines remain robust.

\section{Recent Policy Developments May Presage Change}

Since the withdrawal of sibutramine from the list of approved drugs for the treatment of obesity in 2010 [70], two significant developments in US healthcare policy have occurred, with important implications for the treatment of obesity. First, the PPACA, adopted into law in 2010 [31], strengthened the trend toward financial incentives for improved care and preventive health measures, including the prevention of obesity [71]. Two federal initiatives within PPACA created Accountable Care Organizations (ACOs), particularly the Medicare Shared Savings Program (MSSP) in which individual and organizational healthcare providers assume financial risk for a defined population of elderly and disabled Americans. MSSP ACOs expect to benefit from the shared savings that result from improved quality performance measures [72]. Among the MSSP ACO quality measures are BMI screening and follow-up, which are expected to affect more than 4 million Medicare beneficiaries. The same BMI quality measures are reported to the National Committee on Quality Assurance (NCQA) as part of their ACO accreditation program. As opposed to self-insured providers, MSSP ACOs have required integration and employment of providers within coordinated hospital systems (i.e., vertical healthcare) to achieve improvements in healthcare quality and secondarily reduce costs. In parallel with government-sponsored ACOs, 
commercially insured ACOs have arisen within these systems, which now number close to 1,000 .

In addition to quality measures, incentive programs were provided by the Health Information Technology for Economic and Clinical Health Act (HITECH Act) of 2009 [73] to help integrate patient information from acute care visits, ambulatory encounters, pharmacy, laboratory, imaging, and even genetic and other relevant data through the implementation of efficient Electronic Health Records (EHR) systems. These measures are intended to improve patient safety and outcomes and reduce the costs associated with uncoordinated, unnecessary, or duplicative care. By 2015, incentives for EHR will require meaningful use of data to improve population health [74], creating an ideal environment for the care integration required for effective obesity treatment.

The second significant development came in June of 2013, when the American Medical Association (AMA) recognized obesity as a complex disease $[75,76]$ requiring a range of interventions for effective treatment. Other organizations were more tentative in their approach: new cholesterol and obesity guidelines issued by the American Heart Association, the American College of Cardiology, and The Obesity Society [1] were not endorsed by the American Association of Clinical Endocrinologists (AACE) because the guidelines "fail to classify obesity as a disease and continue the paradigm of BMI-centric risk stratification, both of which are contrary to recently stated AACE positions. Moreover, the guidelines do not include any of the new FDA-approved pharmacologic agents to assist with weight loss" [77]. Regardless, recognition of the complexity of obesity, its multifactorial etiology, and its contribution to increased morbidity and mortality [78] should encourage prevention programs and treatment, and increase access to a range of treatment options [79]. The goal will be a concerted effort by patients, physicians, and payers to address and manage the current obesity epidemic [80, 81].

Together, these policy developments increase incentives for stakeholders to manage obesity more proactively, including through pharmacotherapy, if incremental antiobesity benefit can be provided with appropriate levels of safety. This assumption may not be unlike past health policies focused on chronic health conditions (e.g., excise taxes that raised the price of cigarettes, pharmacological treatment/behavioral support for smoking cessation, indoor smoking bans) that presaged a significant decline in smoking in the USA [82].

\section{Patient and Physician Perspectives: Challenge of Market Demand}

Patient and physician views on obesity present a potential barrier to more systematic use and reimbursement of pharmacotherapy. Patients have historically pursued a number of self-management options for weight loss, including popular diets and commercial programs [83], or other overthe-counter options such as dietary/herbal supplements [84]. Past treatment patterns also indicate that patients take drugs seasonally [85], and do not recognize a role for pharmacologic therapy in maintenance of weight loss. While behavioral and pharmacologic treatments have typically yielded a clinically beneficial [86-89] 5-10\% weight loss, patients frequently expect much greater weight loss [90]. In part, their expectations are conditioned by their desire to return to a prior baseline weight, reflecting an under-appreciation of the social, environmental, and metabolic barriers that make weight loss difficult [90]. Hence, when coupled with lack of insurance reimbursement, there is little long-term adherence to current anti-obesity pharmaceuticals [91].

Physicians' perceptions and views of obesity also have affected treatment patterns for obesity. While there are limited data on physician treatment choices in the primary care setting, surveys have found that physicians recommend counseling for weight loss, including generalized advice on physical activity and diet [92, 93]. Although $92 \%$ of respondents in a 2003 study of primary care physicians viewed obesity as a chronic condition, a much smaller percentage $(26 \%)$ felt that anti-obesity medicines should be used long-term [94]. In a 2007 survey of family physicians in Central New York, respondents typically viewed obesity as a chronic disease [95] and were relatively well aware that a $10 \%$ decrease in total body weight may have significant impact on obesity-related comorbidities, such as hypertension, diabetes, and heart disease [96]. Physicians have traditionally been more comfortable addressing obesity-related co-morbidities [93, 97-99], rather than addressing obesity treatment options, largely because of lack of training in prescribing specific nutrition and physical activity regimens [100]. Given the recent US approval of long-term anti-obesity pharmacotherapies, eHealth options [101], and advances in selfmonitoring technologies [102], it will soon be possible to relieve physicians of some of the barriers of treatment. In addition, there is a need for better treatment guidelines, tools for screening, and better coordination of care, including alignment with public health efforts [95]. These are the very issues that the PPACA and the AMA declaration of the obesity disease model are currently attempting to address through policy changes focused on obesity.

\section{Payer and Employer Perspectives: Challenges of Reimbursement}

Provider reimbursement for surgical management of extreme obesity (BMI $\geq 40 \mathrm{~kg} / \mathrm{m}^{2}$ ) has not only evolved but 
also dramatically increased over the last $10-15$ years. This growth has been fueled by multiple factors, including improved procedures, weight loss, outcomes, and the recognition of extreme obesity as the fastest growing segment of the obese population [103]. While bariatric surgery can significantly improve weight-related co-morbid disease and consequently be life-saving, concerns about the financial burden remain, with average cost estimates approximating \$US20,000 among an eligible US population of 14.5 million adults [103]. In the fragmented US payer environment, with private, government, and employer-based reimbursement systems, and patient movement between these systems (average turnover of 2-3 years), there has been reluctance to pay for bariatric surgery and obesity pharmacotherapy, despite evidence suggesting long-term health benefits and cost effectiveness [103, 104]. The passage of the PPACA and government mandates, such as increased reimbursement for lifestyle/behavioral approaches to obesity treatment, attempt to bypass barriers and may help drive the liberalization of physician treatment reimbursement as well as increased willingness to prescribe antiobesity medication [68, 69]. Additionally, with adequate medication reimbursement, patients stay on anti-obesity drugs longer, see their doctor more often, and lose more weight [105]. The recent AMA declaration of obesity as a disease has also led to prominent policy changes. Recently, the US Office of Personnel Management indicated that federal employees' health benefit plans are not permitted to exclude coverage of newly approved obesity medications on the basis that obesity is a "cosmetic" or "lifestyle" issue; this policy goes into effect in 2015 and will impact 2.7 million federal employees and their beneficiaries [106, 107].

Based on the paucity of data on obesity pharmacotherapy reimbursement across non-governmental payers and the rapidly changing US attitudes toward obesity treatment reimbursement, a survey was undertaken in November 2013, which was funded by Takeda Pharmaceuticals USA, and executed by Strategic Healthcare
Alliance (SHA). The goal of the survey was to determine the current and future plans of healthcare funding entities (employers and private insurance payers) with regard to coverage for obesity treatment. The findings of the study described here provide general direction on this topic, but are based on qualitative research and may not be generalizable to the broader population of payers and healthcare systems. Three 90-min group discussions were held with senior-level representatives from different stakeholder audiences: commercial Managed Care insurance Organizations (MCOs; $n=9$ ), Pharmacy Benefit Managers (PBMs; $n=9$ ), and healthcare providers from Integrated Healthcare Systems (IHSs; $n=10$ ) -all of whom share risk around cost and healthcare outcomes with government and/or commercial payers. SHA provided a list of six levers for respondents to rank by importance (Fig. 1). Overall, respondents agreed that federal/state coverage mandates and the growth of quality-driven healthcare initiatives (that include obesity-related chronic diseases) would be the most significant contributors to broader coverage (Fig. 1). The perception that obesity medication coverage will eventually be mandated by state/federal governments (and adopted by all payers) emerged as an overall theme. MCOs and IHSs cited competitor coverage by other payers and real-world evidence (RWE) pilot programs as intermediary factors encouraging future reimbursement. Not surprisingly, PBMs ranked their support fourth with physician/patient demand as the lowest lever, largely because of their mandate to control pharmaceutical costs. Emergence of the importance surrounding an RWE requirement for future coverage reflects the growing ability to easily collect health outcomes and cost data at the level of the individual providers. Finally, a number of participants indicated an interest in non-traditional coverage options such as risk-share contracts with pharmaceutical manufacturers.

Overall, participants predicted forthcoming access to anti-obesity medication within a 1 - to 5-year time horizon (Fig. 2).
Fig. 1 Payer incentives to provide obesity coverage. HEDIS Healthcare Effectiveness Data and Information Set, IHS Integrated Healthcare Systems, $M C O$ Managed Care Organization, NCQA National Committee for Quality Assurance, $P B M$ Pharmacy Benefits Managers, $R W E$ real-world evidence, STAR Medicare star rating

\begin{tabular}{|c|c|c|c|}
\hline & MCO & IHS & PBM \\
\hline 1 & $\begin{array}{l}\text { Federal/State Coverage } \\
\text { Mandate }\end{array}$ & $\begin{array}{l}\text { Federal/State Coverage } \\
\text { Mandate }\end{array}$ & $\begin{array}{l}\text { Federal/State Coverage } \\
\text { Mandate }\end{array}$ \\
\hline 2 & NCQA/HEDIS/STAR Measures & NCQA/HEDIS/STAR Measures & NCQA/HEDIS/STAR Measures \\
\hline 3 & Competitor Coverage & Pilot Programs for RWE & Pilot Programs for RWE \\
\hline 4 & Pilot Programs for RWE & Competitor Coverage & PBM Support \\
\hline 5 & Physician/Patient Demand & $\begin{array}{l}\text { Demand - of employers vs. } \\
\text { physicians/patients }\end{array}$ & Competitor Coverage \\
\hline 6 & PBM Support & PBM Support & Physician/Patient Demand \\
\hline
\end{tabular}


Fig. 2 Perspectives on coverage time horizon. IHSs Integrated Healthcare Systems, MCOs Managed Care Organizations, PBMs Pharmacy Benefits Managers, yrs years

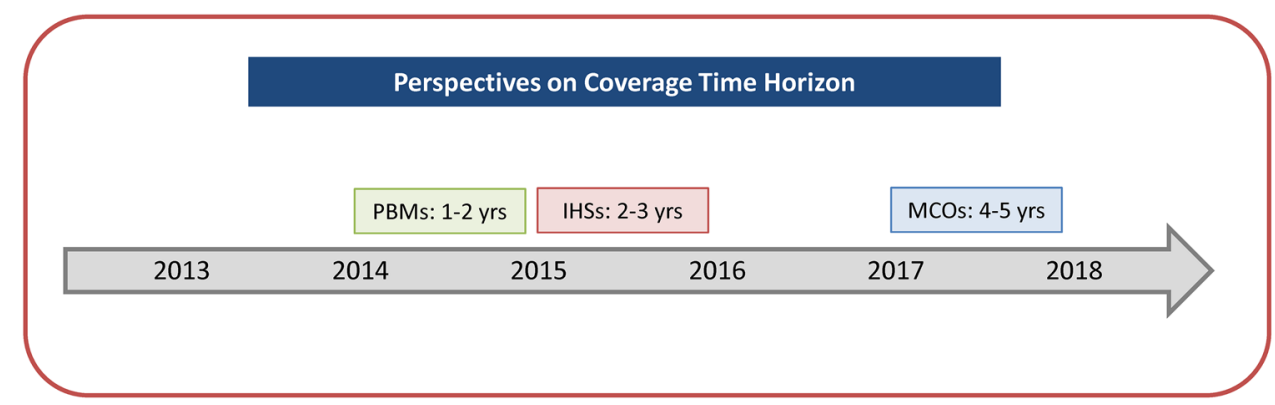

\subsection{Opportunities: Moving Towards Reimbursement}

\subsubsection{Federal/State Coverage Mandates}

In addition to private insurers, there are government programs that provide medical and health-related services at the state and federal levels. Medicare is a nationwide social program that serves 44 million elderly and disabled people, whereas Medicaid serves about 40 million low-income people at the state level [102, 103]. Of note, the most important lever identified by the stakeholder survey included state and federal coverage mandates. At the federal level, the Medicare Prescription Drug, Improvement, and Modernization Act of 2003 (MMA) [108] created the federal prescription drug benefit program Medicare Part D (effective 1 January 2006), which excluded anti-obesity drugs from coverage. The MMA did not recite a list of excluded drugs or classes of drugs; instead, the MMA identified the exclusions by reference to the Medicaid drug rebate provisions in the Omnibus Budget Reconciliation Act of 1990 (OBRA) [109]. Among the drugs "subject to restriction" were "Agents when used for anorexia, weight loss, or weight gain". The Centers for Medicare and Medicaid Services (CMS) further defined this section in guidance [110] issued on 18 July 2008, which clarified there was no Part D coverage for "agents when used for...weight loss...(even if used for a non-cosmetic purpose, i.e. morbid obesity)". However, some private insurance companies with federal contracts to provide Medicare benefits (known as Medicare Advantage plans) are allowed to exceed the scope of the Part D-defined benefit; thus, some Medicare beneficiaries can have covered access to these drugs, although few have implemented coverage. In 2013, legislative efforts were made to amend the MMA to include anti-obesity medication: legislation co-sponsored by a substantial number of members of Congress was introduced in both chambers to allow coverage of weightloss medications under Medicare Part D. The Treat and Reduce Obesity Act of 2013 (H.R. 2415 and S. 1184) [111, 112] amends the MMA to allow coverage of FDA-approved weight-loss drugs. The bill also attempts to address the need to expand covered providers' (i.e., nurse practitioners, behavioral therapists, others) reimbursement for intensive BT. Currently, only primary care providers are eligible for reimbursement, which raises practical concerns about training and the ability to carve out adequate time within a busy primary care practice. The CMS considered the impact of BT on practice time and through coverage constraints created time limits (i.e., $10-15 \mathrm{~min}$ ). Unfortunately, experts in BT have raised concerns about the efficacy of short-term BT interventions [113]. Although the bills died in December 2014 when the 113th Congress adjourned, the legislation will be reintroduced in the 114th Congress. However, as reported by GovTrack (https:// www.govtrack.us/), a government transparency website, any bill has a very low chance of being enacted in the near future given the large number of bills introduced each year.

At the state level, programs may elect to cover (either through state directives or statute) [114] obesity treatments for Medicaid patients, but they are not required to do so per OBRA 1990. In addition, state governments legislate, regulate, and purchase/pay for healthcare for their employees and retirees. State fiscal pressures and the rising cost of total healthcare for their citizens has prompted states to more closely consider the benefits of implementing wellness programs that include coverage of smoking cessation, stress management, and weight-loss management (e.g., New York [115]). In addition, the implementation of federal healthcare recommendations at the state level has also affected the coverage offered by commercial health plans, though not in a uniform manner [116]. Most states do have health promotion initiatives in place for nonMedicaid citizens, but no standards of care mandate that insurance offerings in the private marketplace must cover weight-loss medicines. Yet, some states have elected to provide insurance coverage for weight-loss treatments for their employees and retirees [114]. Whereas at least 23 states, as of 2012, provided wellness programs for their employees (such as screening for cholesterol, glucose, blood pressure, and BMI), only a few currently provide incentives for weight loss and/or coverage of weight-loss therapies. These states also may provide health coaching for weight management (e.g., the Kansas HealthQuest Health and Wellness program). 


\subsubsection{Measures of Treatment Performance}

The next important factor in obesity reimbursement is the availability of quality measures, which can track obesity treatment outcomes. There are obesity performance measures within the Federal ACO MSSP and the Medicare Star Ratings System for the percentage of patients with a recorded BMI and the documentation of a follow-up plan in patients 18 years and older with a BMI outside the normal range. Also included are additional performance standards for obesity-associated co-morbidities, such as diabetes (e.g., glycated hemoglobin control and low density lipoprotein control), hypertension (e.g., controlling high blood pressure), and coronary artery disease (e.g., lipid control). There are financial incentives provided to physicians when a desired performance level is met $[117,118]$. Finally, the Healthcare Effectiveness Data and Information Set (HEDIS), sponsored by the NCQA, is used by various payers to measure performance on care and service; HEDIS includes in its measures an adult BMI assessment and a child/adolescent measure focused on weight assessment and counseling for nutrition and physical activity [119]. Reporting the results of HEDIS measures allows the purchasers of healthcare to compare the relative quality of commercial, Medicaid, and Medicare plans. As new and evolving obesity treatment approaches gain traction in clinical practice, additional outcomes and quality measures related to weight-loss treatment will likely be added to these quality performance panels. For now, the focus on BMI and obesity-related co-morbidities is an important first step in encouraging disease prevention.

\subsubsection{Employer Initiatives}

Anti-obesity coverage for employees of private companies is more variable. According to the US Census, in 2013 more than half (i.e., $54 \%$ ) of Americans had employmentbased health insurance [120]. Consequently, employers have enormous influence over insurance coverage. Payer research indicates that only larger employers who fully subsidize employees' healthcare (self-insured employers) with co-pay offsets borne by the subscriber purchase additional coverage outside standard benefits (insurance riders). Thus, obesity coverage for many Americans is limited. Payers have indicated that generally an obesity rider is not directly requested; rather, employers specify that they believe obesity is a problem in their population and that they would like information on management options. Approximately $60 \%$ of current plans $(n=99$, based on large regional and national plans and PBMs) do not cover anti-obesity medications [68]. Yet, over $50 \%$ of employers offer wellness programs, largely as a way to foster employee loyalty, but with little evidence of health improvements or reduced cost [121]. For pharmaceutical manufacturers, shifting the employer focus from wellness offerings to clinical interventions targeting overweight and obese employees will require real-world studies that examine the role of structured weight-loss interventions on cost savings (similar to recent studies, but within employer groups).

\section{Future Directions}

The recognition of obesity as a complex disease with multiple co-morbidities and expensive consequences is driving research into the development of effective treatment options. Emerging evidence suggests that the best outcomes derive from multidisciplinary approaches that utilize a broad range of expertise and varied interventions with proven synergy [42]. Combination weight-management programs coupled with innovative, promising eHealth programs [122], behavioral incentives [44, 123], and health-promoting policy decisions [31, 72, 76, 77] should continue to undergo real-world clinical and economic evaluation. Historically, the perception of obesity as a lifestyle concern led payers to limit coverage and physicians to limit prescribing. The scarcity of information about effective treatment options and clinical outcome benchmarks resulted in patient-driven demand (or lack of demand) for certain treatments and unrealistic expectations of therapy success. Today, however, the consequences of obesity are understood as both clinically and economically relevant, and obesity itself is no longer considered merely a lifestyle issue. As data emerge on the cost benefit of medical weight management, barriers to managed care coverage will likely decline.

Further research, particularly focusing on outcomes and economic benefits in real-world settings, needs to be conducted on all proposed approaches, whether primary prevention, lifestyle- or behavior-focused clinical interventions, surgical or pharmacologic interventions, or a combination. The creation of quality metrics and datadriven healthcare community practice will formulate this effort. Other innovative approaches that demonstrate value, such as risk- or outcomes-based contracting between insurers and manufacturers, may help drive innovation and hasten the evolution of the value proposition needed to persuade payers, employers, providers, and patients of the benefits of pharmacotherapy.

Acknowledgments The authors acknowledge the contributions of Ana Bozas, Ph.D., Analysis Group, Inc., Boston, MA, USA, Edward G. Tuttle, M.A., M.B.A., Analysis Group, Inc., Menlo Park, CA, USA, and Theresa Peterson, Ph.D., Takeda Pharmaceuticals U.S.A, Deerfield, IL, USA, for assistance in the preparation of this manuscript. 
Authors' contributions RT led the development of the initial outline and KA was responsible for acquisition of survey data. All authors contributed writing to the initial as well as subsequent drafts of the paper and critically reviewed and approved the final paper. CB is the guarantor for the overall content of the manuscript.

Funding and other disclosures statement This study was funded by Takeda. CB, KA, EW, SS, KS, and RT are employees of Takeda and own stock/stock options.

Open Access This article is distributed under the terms of the Creative Commons Attribution Noncommercial License which permits any noncommercial use, distribution, and reproduction in any medium, provided the original author(s) and the source are credited.

\section{References}

1. Jensen MD, Ryan DH, Apovian CM, Ard JD, Comuzzie AG, Donato KA, et al. 2013 AHA/ACC/TOS guideline for the management of overweight and obesity in adults: a report of the American College of Cardiology/American Heart Association Task Force on Practice Guidelines and The Obesity Society. Circulation. 2014;129(25 Suppl 2):S102-38.

2. Organization for Economic Co-operation and Development. Obesity and the economics of prevention. Geneva: Organization for Economic Co-operation and Development Publishing; 2010.

3. Organization for the Economic Co-operation and Development. Obesity update. June 2014. June 2014. http://www.oecd.org/els/ health-systems/Obesity-Update-2014.pdf. Accessed 29 July 2014.

4. Wang Y, Beydoun MA. The obesity epidemic in the United States-gender, age, socioeconomic, racial/ethnic, and geographic characteristics: a systematic review and meta-regression analysis. Epidemiol Rev. 2007;29:6-28.

5. Mitchell NS, Catenacci VA, Wyatt HR, Hill JO. Obesity: overview of an epidemic. Psychiatr Clin North Am. 2011;34(4):717-32.

6. Komlos J, Brabec M. The trend of mean BMI values of US adults, birth cohorts 1882-1986 indicates that the obesity epidemic began earlier than hitherto thought. Am J Hum Biol. 2010;22(5):631-8.

7. Office of the Surgeon General (US); Office of Disease Prevention and Health Promotion (US); Centers for Disease Control and Prevention (US); National Institutes of Health (US). The Surgeon General's call to action to prevent and decrease overweight and obesity. Rockville: office of the Surgeon General (US); 2001. http://www.ncbi.nlm.nih.gov/pubmed/20669513. Accessed 28 May 2014.

8. Swinburn BA, Caterson I, Seidell JC, James WPT. Diet, nutrition and the prevention of excess weight gain and obesity. Public Health Nutr. 2004;7(1A):123-46.

9. Hill JO. Can a small-changes approach help address the obesity epidemic? A report of the Joint Task Force of the American Society for Nutrition, Institute of Food Technologists, and International Food Information Council. Am J Clin Nutr. 2009;89(2):477-84.

10. Wilde PE. Federal communication about obesity in the Dietary Guidelines and checkoff programs. Obesity (Silver Spring). 2006;14(6):967-73.

11. Office for State, tribal, local and territorial support. Nutrition, physical activity, and obesity. In: Centers for Disease Control and Prevention. Prevention Status Reports (PSR). 2013. http:// www.cdc.gov/stltpublichealth/psr/npao/index.html. Accessed 29 May 2014.

12. National Center for Chronic Disease Prevention and Health Promotion, Division of Nutrition Physical Activity and Obesity, Centers for Disease Control and Prevention. State indicator report on fruits and vegetables, 2013. National action guide. http:// www.cdc.gov/nutrition/downloads/national-action-guide2013. pdf. Accessed 29 May 2014.

13. Dietz WH, Benken DE, Hunter AS. Public health law and the prevention and control of obesity. Milbank Q. 2009;87(1): 215-27.

14. Mello MM, Studdert DM, Brennan TA. Obesity-the new frontier of public health law. N Engl J Med. 2006;354(24):2601-10.

15. Obesity Education Initiative, National Institutes of Health. Clinical guidelines on the identification, evaluation, and treatment of overweight and obesity in adults: the evidence report. National Institutes of Health. Sep 1998. http://www.nhlbi.nih. gov/files/docs/guidelines/ob_gdlns.pdf. Accessed 5 May 2014.

16. Rippe JM. The case for medical management of obesity: a call for increased physician involvement. Obes Res. 1998;6(Suppl 1):23S-33S.

17. Lemmens VEPP, Oenema A, Klepp KI, Henriksen HB, Brug J. A systematic review of the evidence regarding efficacy of obesity prevention interventions among adults. Obes Rev. 2008;9(5):446-55.

18. Lombard CB, Deeks AA, Teede HJ. A systematic review of interventions aimed at the prevention of weight gain in adults. Public Health Nutr. 2009;12(11):2236-46.

19. Brown T, Summerbell C. Systematic review of school-based interventions that focus on changing dietary intake and physical activity levels to prevent childhood obesity: an update to the obesity guidance produced by the National Institute for Health and Clinical Excellence. Obes Rev. 2009;10(1):110-41.

20. Wolf AM, Woodworth KA. Obesity prevention: recommended strategies and challenges. Am J Med. 2009;122(4 Suppl 1):S19-23.

21. Knowler WC, Barrett-Connor E, Fowler SE, Hamman RF, Lachin JM, Walker EA, et al. Reduction in the incidence of type 2 diabetes with lifestyle intervention or metformin. N Engl J Med. 2002;346(6):393-403.

22. Knowler WC, Fowler SE, Hamman RF, Christophi CA, Hoffman HJ, Brenneman AT, et al. 10-year follow-up of diabetes incidence and weight loss in the Diabetes Prevention Program Outcomes Study. Lancet. 2009;374(9702):1677-86.

23. Moore AF, Jablonski KA, Mason CC, McAteer JB, Arakaki RF, Goldstein BJ, et al. The association of ENPP1 K121Q with diabetes incidence is abolished by lifestyle modification in the diabetes prevention program. J Clin Endocrinol Metab. 2009;94(2):449-55.

24. Wing RR, Lang W, Wadden TA, Safford M, Knowler WC, Bertoni AG, et al. Benefits of modest weight loss in improving cardiovascular risk factors in overweight and obese individuals with type 2 diabetes. Diabetes Care. 2011;34(7):1481-6.

25. Korytkowski MT. Lessons from the look action for health in diabetes study. Indian J Endocrinol Metab. 2013;17(Suppl 3):S650-3.

26. Loveman E, Frampton GK, Shepherd J, Picot J, Cooper K, Bryant $\mathrm{J}$, et al. The clinical effectiveness and cost-effectiveness of long-term weight management schemes for adults: a systematic review. Health Technol Assess. 2011;15(2):1-182.

27. Allison DB, Downey M, Atkinson RL, Billington CJ, Bray GA, Eckel RH, et al. Obesity as a disease: a white paper on evidence and arguments commissioned by the Council of the Obesity Society. Obesity (Silver Spring). 2008;16(6):1161-77.

28. Pi-Sunyer X. The medical risks of obesity. Postgrad Med. 2009;121(6):21-33. 
29. Garber AJ, Abrahamson MJ, Barzilay JI, Blonde L, Bloomgarden ZT, Bush MA, et al. AACE comprehensive diabetes management algorithm 2013. Endocr Pract. 2013;19(2):327-36.

30. Alexander SC, Cox ME, Boling Turer CL, Lyna P, Østbye T, Tulsky JA, et al. Do the five A's work when physicians counsel about weight loss? Fam Med. 2011;43(3):179-84.

31. H.R. 3590-111th Congress: Patient Protection and Affordable Care Act. Public Law No. 111-148. 124 Stat. 119-1025. 23 March 2010. http://www.gpo.gov/fdsys/pkg/BILLS-111hr3590 enr/pdf/BILLS-111hr3590enr.pdf. Accessed 6 May 2014.

32. Skinner AC, Skelton JA. Prevalence and trends in obesity and severe obesity among children in the United States, 1999-2012. JAMA Pediatr. 2014;168(6):561-6.

33. Zhao Y, Encinosa W. Bariatric surgery utilization and outcomes in 1998 and 2004. HCUP Statistical Brief \#23. Agency for Healthcare Research and Quality. January 2007. http://www. hcup-us.ahrq.gov/reports/statbriefs/sb23.pdf. Accessed 11 Dec 2014.

34. U.S. Food and Drug Administration. FDA expands use of banding system for weight loss [press Announcement]. $2011 \mathrm{Feb}$ 16. http://www.fda.gov/NewsEvents/Newsroom/PressAnnounce ments/ucm245617.htm. Accessed 11 Dec 2014.

35. O'Brien PE, MacDonald L, Anderson M, Brennan L, Brown WA. Long-term outcomes after bariatric surgery: fifteen-year followup of adjustable gastric banding and a systematic review of the bariatric surgical literature. Ann Surg. 2013;257(1):87-94.

36. Picot J, Jones J, Colquitt JL, Gospodarevskaya E, Loveman E, Baxter L, et al. The clinical effectiveness and cost-effectiveness of bariatric (weight loss) surgery for obesity: a systematic review and economic evaluation. Health Technol Assess (Rockv). 2009;13(41):1-190, 215-357, 3-4.

37. Maggard MA, Shugarman LR, Suttorp M, Maglione M, Sugerman HJ, Sugarman HJ, et al. Meta-analysis: surgical treatment of obesity. Ann Intern Med. 2005;142(7):547-59.

38. Karmali S, Brar B, Shi X, Sharma AM, de Gara C, Birch DW. Weight recidivism post-bariatric surgery: a systematic review. Obes Surg. 2013;23(11):1922-33.

39. Hsu LK, Benotti PN, Dwyer J, Roberts SB, Saltzman E, Shikora $\mathrm{S}$, et al. Nonsurgical factors that influence the outcome of bariatric surgery: a review. Psychosom Med. 1998;60(3):338-46.

40. Brethauer SA, Kothari S, Sudan R, Williams B, English WJ, Brengman M, et al. Systematic review on reoperative bariatric surgery: American Society for Metabolic and Bariatric Surgery Revision Task Force. Surg Obes Relat Dis. 2014;10(5):952-72. doi:10.1016/j.soard.2014.02.014.

41. Steinberg DM, Tate DF, Bennett GG, Ennett S, Samuel-Hodge $\mathrm{C}$, Ward DS. The efficacy of a daily self-weighing weight loss intervention using smart scales and e-mail. Obesity (Silver Spring). 2013;21(9):1789-97.

42. Yanovski SZ, Yanovski JA. Long-term drug treatment for obesity: a systematic and clinical review. JAMA. 2014;311(1):74-86.

43. Finkelstein EAE, Trogdon JGJ, Cohen JJW, Dietz W. Annual medical spending attributable to obesity: payer-and servicespecific estimates. Health Aff. 2009;28(5):w822-31.

44. Rothberg AE, McEwen LN, Fraser T, Burant CF, Herman WH. The impact of a managed care obesity intervention on clinical outcomes and costs: a prospective observational study. Obesity (Silver Spring). 2013;21(11):2157-62. http://www. pubmedcentral.nih.gov/articlerender.fcgi?artid=3947418\&tool= pmcentrez\&rendertype=abstract. Accessed 5 May 2014.

45. Colman E. Anorectics on trial: a half century of federal regulation of prescription appetite suppressants. Ann Intern Med. 2005;143(5):380-5.

46. Stamler J. Epidemic obesity in the United States. Arch Intern Med. 1993;153(9):1040-4.
47. Lexchin J. Lifestyle drugs: issues for debate. CMAJ. 2001;164(10):1449-51.

48. Yale C. Reporting our results. Obes Surg. 1991;1(3):241-2.

49. Cohen K. Fen phen nation. In: Frontline. WGBH Educational Foundation. 2003 Nov 13. http://www.pbs.org/wgbh/pages/ frontline/shows/prescription/hazard/fenphen.html. Accessed 30 May 2014.

50. Meyer BR. Powerful medicines: the benefits, risks, and costs of prescription drugs. Ann Intern Med. 2005;142(1):80.

51. Center for Drug Evaluation and Research, U.S. Food and Drug Administration. FDA announces withdrawal fenfluramine and dexfenfluramine (fen-phen). In: Postmarket Drug Safety Information for Patients and Providers. Center for Drug Evaluation and Research, U.S. Food and Drug Administration. 1997. http:// www.fda.gov/Drugs/DrugSafety/

PostmarketDrugSafetyInformationforPatientsandProviders/ ucm179871.htm. Accessed 30 May 2014.

52. McBay DL, Dourish CT. Obesity-the 21st century disease. Drug Discov World. 2002;18-24.

53. Thomson Reuters. Spotlight on...obesity. A pharma matters report. Oct-Dec 2010. http://ip-science.thomsonreuters.com.au/ m/pdf/SpotlightOn_cwp_Q4_10.pdf. Accessed 6 May 2014.

54. Wong D, Sullivan K, Heap G. The pharmaceutical market for obesity therapies. Nat Rev Drug Discov. 2012;11(9):669-70.

55. U.S. Food and Drug Administration. FDA approves Belviq to treat some overweight or obese adults. In: Press Announcements. U.S. Food and Drug Administration. 2012. http://www. fda.gov/NewsEvents/Newsroom/PressAnnouncements/ ucm309993.htm. Accessed 29 July 2014.

56. U.S. Food and Drug Administration. FDA approves weightmanagement drug Qsymia. In: Press Announcements. U.S. Food and Drug Administration. 2012. http://www.fda.gov/newsevents/ newsroom/pressannouncements/ucm 312468.htm. Accessed 3 June 2014

57. U.S. Food and Drug Administration. FDA approves weightmanagement drug Contrave. In: Press Announcements. U.S. Food and Drug Administration. 2014. http://www.fda.gov/ NewsEvents/Newsroom/PressAnnouncements/ucm413896.htm. Accessed 11 Dec 2014.

58. Goozner M. FDA increases focus on postmarketing studies. J Natl Cancer Inst. 2010;102(17):1302-4.

59. DiMasi JA, Feldman L, Seckler A, Wilson A. Trends in risks associated with new drug development: success rates for investigational drugs. Clin Pharmacol Ther. 2010;87(3):272-7.

60. Kola I, Landis J. Can the pharmaceutical industry reduce attrition rates? Nat Rev drug Discov. 2004;3(8):711-5.

61. Adams CP, Brantner VV. Spending on new drug development. Health Econ. 2010;19(2):130-41.

62. Vernon JA, Golec JH, Dimasi JA. Drug development costs when financial risk is measured using the Fama-French three-factor model. Health Econ. 2010;19(8):1002-5.

63. Morgan S, Grootendorst P, Lexchin J, Cunningham C, Greyson D. The cost of drug development: a systematic review. Health Policy. 2011;100(1):4-17.

64. Heal DJ, Gosden J, Smith SL. Regulatory challenges for new drugs to treat obesity and comorbid metabolic disorders. Br J Clin Pharmacol. 2009;68(6):861-74.

65. Hayes WS. Bridging the evidence gap to treat obesity. In: Hayes Blog. Winifred S. Hayes, Inc. 2013. http://www.hayesinc.com/ hayes/blog/blog-bridging-the-evidence-gap-to-treat-obesity/. Accessed 3 June 2014

66. Snow V, Barry P, Fitterman N, Qaseem A, Weiss K. Pharmacologic and surgical management of obesity in primary care: a clinical practice guideline from the American College of Physicians. Ann Intern Med. 2005;142(7):525. 
67. ECRI Institute. Priority area 10: obesity. AHRQ Healthcare Horizon Scanning System-potential high-impact interventions report. Rockville: Agency for Healthcare Research and Quality, U.S. Department of Health and Human Services; 2013 Dec. http://effectivehealthcare.ahrq.gov/ehc/assets/File/ObesityHorizon-Scan-High-Impact-1312.pdf. Accessed 15 May 2014.

68. Greenapple R, Ngai J. Obesity: effective treatment requires change in payers' perspective. Am Heal Drug Benefits. 2010;3(2):88-94.

69. Verger P, Rolland S, Paraponaris A, Bouvenot J, Ventelou B. Drug reimbursement and GPs' prescribing decisions: a randomized case-vignette study about the pharmacotherapy of obesity associated with type 2 diabetes: how GPs react to drug reimbursement. Fundam Clin Pharmacol. 2010;24(4):509-16.

70. U.S. Food and Drug Administration. Meridia (sibutramine): market withdrawal due to risk of serious cardiovascular events. In: Safety alerts for human medical products. U.S. Food and Drug Administration. 2010. http://www.fda.gov/safety/ medwatch/safetyinformation/safetyalertsforhumanmedical products/ucm228830.htm. Accessed 29 July 2014.

71. Yang YT, Nichols LM. Obesity and health system reform: private vs. public responsibility. J Law Med Ethics. 2011;39(3):380-6.

72. Epstein AM, Jha AK, Orav EJ, Liebman DL, Audet A-MJ, Zezza MA, et al. Analysis of early accountable care organizations defines patient, structural, cost, and quality-of-care characteristics. Health Aff (Millwood). 2014;33(1):95-102.

73. Health Information Technology for Economic and Clinical Health Act. 123 Stat. 226, 467. 17 February 2009. http://www. gpo.gov/fdsys/pkg/BILLS-111hr1enr/pdf/BILLS-111hrlenr.pdf. Accessed 6 May 2014.

74. Centers for Medicare and Medicaid Services. EHR incentive programs. In: CMS-regulations and guidance. Centers for Medicare and Medicaid Services. 2014. http://www.cms.gov/ Regulations-and-Guidance/Legislation/EHRIncentivePrograms/ index.html?redirect=/ehrincentiveprograms/. Accessed 6 May 2014.

75. American Medical Association Council on Science and Public Health, American Medical Association. Recognition of Obesity as a Disease. Resolution: 421(A-13). American Medical Association. May 2013. http://media.npr.org/documents/2013/jun/ ama-resolution-obesity.pdf. Accessed 6 May 2014.

76. Zuzek C. Obesity is a disease. Tex Med. 2014;110(1):45-8.

77. The American Association of Clinical Endocrinologists. Press Statement [AACE letter to members regarding updated guidelines on lipids and obesity by AHA/ACC/TOS]. 2013. https:// www.aace.com/sites/all/files/Member_Alert_Re_Guidelines_ 112113.pdf. Accessed 6 May 2014

78. Rippe JM, Crossley S, Ringer R. Obesity as a chronic disease: modern medical and lifestyle management. J Am Diet Assoc. 1998;98(10 Suppl 2):S9-15.

79. Obesity as a disease: the Obesity Society Council resolution. Obesity (Silver Spring). 2008;16(6):1151.

80. Kopelman PG. Obesity as a medical problem. Nature. 2000;404(6778):635-43.

81. Conway B, Rene A. Obesity as a disease: no lightweight matter. Obes Rev. 2004;5(3):145-51.

82. Engelhard CL, Garson A, Dorn S. Reducing obesity: policy strategies from the tobacco wars. Methodist Debakey Cardiovasc J. 2009;5(4):46-50.

83. Rao G. Office-based strategies for the management of obesity. Am Fam Physician. 2010;81(12):1449-56 (quiz 1429).

84. Bray GA. Are non-prescription medications needed for weight control? Obesity (Silver Spring). 2008;16(3):509-14.

85. Patterson L, Patterson C, Kee F, Hughes C, Donnelly M, O'Reilly D. Prescribing for weight loss in primary care: evidence from a population based study. J Epidemiol Community Health. 2013;67(6):530-2.

86. Blackburn G. Effect of degree of weight loss on health benefits. Obes Res. 1995;3(S2):211s-6s.

87. Goldstein DJ. Beneficial health effects of modest weight loss. Int J Obes Relat Metab Disord. 1992;16(6):397-415.

88. Van Gaal LF. What is the relationship between risk factor reduction and degree of weight loss? Eur Hear J Suppl. 2005;7(Suppl L):L21-6.

89. Varady KA, Tussing L, Bhutani S, Braunschweig CL. Degree of weight loss required to improve adipokine concentrations and decrease fat cell size in severely obese women. Metabolism. 2009;58(8):1096-101.

90. Foster GD, Wadden TA, Phelan S, Sarwer DB, Sanderson RS. Obese patients' perceptions of treatment outcomes and the factors that influence them. Arch Intern Med. 2001;161(17):2133-9.

91. Hemo B, Endevelt R, Porath A, Stampfer MJ, Shai I. Adherence to weight loss medications; post-marketing study from HMO pharmacy data of one million individuals. Diabetes Res Clin Pract. 2011;94(2):269-75.

92. Phelan S, Nallari M, Darroch FE, Wing RR. What do physicians recommend to their overweight and obese patients? J Am Board Fam Med. 2009;22(2):115-22.

93. Stafford RS, Farhat JH, Misra B, Schoenfeld DA. National patterns of physician activities related to obesity management. Arch Fam Med. 2000;9(7):631-8.

94. Foster GD, Wadden TA, Makris AP, Davidson D, Sanderson RS, Allison DB, et al. Primary care physicians' attitudes about obesity and its treatment. Obes Res. 2003;11(10):1168-77.

95. Epling JW, Morley CP, Ploutz-Snyder R. Family physician attitudes in managing obesity: a cross-sectional survey study. BMC Res Notes. 2011;4:473.

96. Yanovski SZ, Yanovski JA. Obesity. N Engl J Med. 2002;346(8):591-602.

97. Bleich SN, Pickett-Blakely O, Cooper LA. Physician practice patterns of obesity diagnosis and weight-related counseling. Patient Educ Couns. 2011;82(1):123-9.

98. Lazorick S, Peaker B, Perrin EM, Schmid D, Pennington T, Yow A, et al. Prevention and treatment of childhood obesity: care received by a state Medicaid population. Clin Pediatr (Phila). 2011;50(9):816-26.

99. Tham M, Young D. The role of the General Practitioner in weight management in primary care-a cross sectional study in General Practice. BMC Fam Pract. 2008;9:66.

100. Forman-Hoffman V, Little A, Wahls T. Barriers to obesity management: a pilot study of primary care clinicians. BMC Fam Pract. 2006;7:35.

101. Bennett GG, Steinberg DM, Stoute C, Lanpher M, Lane I, Askew S, et al. Electronic health (eHealth) interventions for weight management among racial/ethnic minority adults: a systematic review. Obes Rev. 2014;15(Suppl 4):146-58.

102. Yeager SF, Heim R, Seiler J, Lofton H. Self-monitoring-the way to successful weight management. Your Weight Matters Magazine. 2014;5. http://www.obesityaction.org/educationalresources/resource-articles-2/weight-loss-surgery/self-monitoringthe-way-to-successful-weight-management. Accessed 11 Dec 2014.

103. Holtorf A, Rinde H, Rupprecht F, Alder H, Brixner D. The economic impact of bariatric surgery, advanced bariatric and metabolic surgery. In: Huang C-K, editor. Rijeka: InTech; 2012.

104. Finkelstein EA, Kruger E. Meta- and cost-effectiveness analysis of commercial weight loss strategies. Obesity (Silver Spring). 2014;22(9): 1942-51.

105. Risser JA, Vash PD, Nieto L. Does prior authorization of sibutramine improve medication compliance or weight loss? Obes Res. 2005;13(1):86-92. 
106. U.S. Office of Personnel Management Healthcare and Insurance. Supplemental guidance: management of obesity in adults. In: FEHB Program Carrier Letter. 2014. http://www.opm.gov/ healthcare-insurance/healthcare/carriers/2014/2014-04.pdf. Accessed 29 July 2014.

107. The Advisory Board Company. Feds offer guidance on how to cover obesity treatment-OPM sets standards of federal employee health plans. In: Daily Briefing. The Advisory Board Company. 2014. http://www.advisory.com/daily-briefing/2014/ 04/03/feds-offer-guidance-on-how-to-cover-obesity-treatment. Accessed 5 May 2014.

108. Medicare Prescription Drug, Improvement, and Modernization Act of 2003. Public Law No. 108-173. 2003. http://www.gpo. gov/fdsys/pkg/PLAW-108publ173/html/PLAW-108publ173. htm. Accessed 29 July 2014.

109. The Omnibus Budget Reconciliation Act of 1990. Sec 1927(d)(2). 1990. http://www.ssa.gov/OP_Home/ssact/title19/ 1927.htm. Accessed 5 May 2014.

110. Department of Health and Human Services (DHHS), Centers for Medicare and Medicaid Services (CMS). Chapter 6-Part D Drugs and Formulary Requirements. CMS Manual System Pub. 100-18: Medicare Prescription Drug Benefit Manual. July 2008. http://www.cms.gov/Regulations-and-Guidance/Guidance/ Transmittals/downloads/R2PDB.pdf. Accessed 5 May 2014.

111. S. 1184-113th Congress: Treat and Reduce Obesity Act of 2013. 2013. http://www.govtrack.us/congress/bills/113/s1184. Accessed 5 May 2014.

112. H.R. 2415: Treat and Reduce Obesity Act of 2013. 2013. https:// www.govtrack.us/congress/bills/113/hr2415. Accessed 5 May 2014.

113. Carvajal R, Wadden TA, Tsai AG, Peck K, Moran CH. Managing obesity in primary care practice: a narrative review. Ann NY Acad Sci. 2013;1281:191-206.

114. Lee JS, Sheer JLO, Lopez N, Rosenbaum S. Coverage of obesity treatment: a state-by-state analysis of Medicaid and state insurance laws. Public Health Rep. 2010;125(4):596-604.

115. New York State Department of Health. Specific strategies. In: Strategic plan for overweight and obesity prevention. New York State Department of Health. 2014. http://www.aging.ny.gov/ news/2013/Strategic_plan\%20NYSDOH\%20Obesity\%202005. pdf. Accessed 29 May 2014.
116. U.S. Centers for Disease Control and Prevention. Health plan implementation of U.S. Preventive Services Task Force A and B recommendations-Colorado, 2010. MMWR Morb Mortal Wkly Rep. 2011;60(39):1348-50.

117. RTI International, Telligen. Accountable Care Organization 2013 program analysis. Quality performance standards narrative measure specifications. Centers for Medicare and Medicaid Services. December 2012. http://www.cms.gov/Medicare/ Medicare-Fee-for-Service-Payment/sharedsavingsprogram/ Downloads/ACO-NarrativeMeasures-Specs.pdf. Accessed 5 May 2014.

118. Centers for Medicare and Medicaid Services. Part C and D performance data. In: Prescription Drug Coverage-General Information. Centers for Medicare and Medicaid Services. 2014. http://www.cms.gov/Medicare/Prescription-Drug-Coverage/ PrescriptionDrugCovGenIn/PerformanceData.html. Accessed 5 May 2014.

119. National Committee for Quality Assurance (NCQA). Summary table of measures, product lines and changes. In: HEDIS 2014. Healthcare Effectiveness Data and Information Set (HEDIS). 2014. http://www.ncqa.org/Portals/0/HEDISQM/HEDIS2014/ List_of_HEDIS_2014_Measures.pdf. Accessed 5 May 2014.

120. DeNavas-Walt C, Proctor BD, Smith JC. Income, poverty, and health insurance coverage in the United States: 2011. U.S. Census Bureau, Current Population Reports, P60-243. U.S. Government Printing Office. September 2012. http://www. census.gov/prod/2012pubs/p60-243.pdf. Accessed 10 July 2014.

121. Horwitz JR, Kelly BD, DiNardo JE. Wellness incentives in the workplace: cost savings through cost shifting to unhealthy workers. Health Aff (Millwood). 2013;32(3):468-76.

122. Neve M, Morgan PJ, Jones PR, Collins CE. Effectiveness of web-based interventions in achieving weight loss and weight loss maintenance in overweight and obese adults: a systematic review with meta-analysis. Obes Rev. 2010;11(4):306-21.

123. Leahey TM, Subak LL, Fava J, Schembri M, Thomas G, Xu X, et al. Benefits of adding small financial incentives or optional group meetings to a web-based statewide obesity initiative. Obesity (Silver Spring). 2015;23(1):70-6. doi:10.1002/oby. 20937. 